\title{
Künstliche Intelligenz - überschätzt oder unterschätzt? Ja!
}

Künstliche Intelligenz (KI) oder wie man heute neudeutsch oft sagt AI (also „artificial intelligence“) fasziniert die Menschen seit Langem, sie weckt Hoffnungen und Ängste zugleich. Maschinen, die körperliche Arbeiten übernehmen und besser durchführen können als der Mensch, gehören schon lange zu unserem Alltag. Sie machen keine Angst (mehr). Anders sieht das bei „Maschinen“ aus, die für uns das Denken übernehmen. Die Vorstellung, eine künstliche Intelligenz könne den Menschen ersetzen, gar überflügeln, stellt eine Kränkung der menschlichen Eitelkeit dar - wir stoßen uns selbst vom Thron, auf den wir uns so lange gesetzt haben.

Tatsächlich kann Software heute besser Schach und sogar Go spielen als jeder Mensch - Letzteres wurde noch vor Kurzem für nahezu ausgeschlossen gehalten. Andererseits ist KI heute noch sehr weit entfernt davon, die Vorstellungen von Robotern Wirklichkeit werden zu lassen, die sich nicht von Menschen unterscheiden oder diesen gar überlegen sind, wie wir sie aus Science-Fiction-Filmen kennen. Heute wird KI gleichzeitig über- und unterschätzt, was verhindert, dass viele Menschen eine realistische Vorstellung davon haben, wo und wie sie bereits heute sinnvoll eingesetzt werden kann.

Die Bandbreite ist groß und oft kann KI sehr nützlich sein. Andererseits gibt es, wie bei jedem Hype, eine Neigung, alles mit der neuen Technologie lösen zu wollen, weil man das neue „Spielzeug“ so faszinierend findet (Ähnliches kann man zum Beispiel bei der Blockchain-Technologie beobachten). Vor diesem Hintergrund ist eine wichtige Forderung, dass möglichst viele Menschen besser verstehen, was KI eigentlich ist, wo Chancen und Herausforderungen tatsächlich liegen. Hoffentlich trägt das Lesen der Beiträge in dieser Ausgabe dazu bei, dass Sie eine genauere Vorstellung davon bekommen, was KI heute kann und in Zukunft können wird.

Ich wünsche Ihnen eine angenehme und erhellende Lektüre

Chefredakteur

Wirtschaftsinformatik \& Management 2020 • 12 (2): 63 https://doi.org/10.1365/s35764-020-00253-3

Online publiziert: 6. März 2020

(c) Springer Fachmedien Wiesbaden GmbH, ein Teil von Springer Nature 2020 